\title{
In Vitro Antioxidant Activity of Withania Somnifera Root
}

\author{
1,2 Ratan Kumar Paul \\ ${ }^{1}$ Department of Chemistry, Pabna University of Science and Technology, Pabna, Bangladesh \\ ${ }^{2}$ Department of Chemistry, Bangladesh University of Engineering \& Technology, Dhaka, \\ Bangladesh \\ ratanpaul05@yahoo.com
}

\section{Homayun Kabir}

Department of Chemistry, Pabna University of Science and Technology, Pabna, Bangladesh.

kabirchem07@gmail.com

Md. Saifur Rahaman

Institute of Radiation and Polymer Technology, Atomic Energy Research Establishment, Bangladesh Atomic Energy

Commission, Dhaka, Bangladesh. msrchesust@gmail.com

\section{Debu Kumar Bhattacharjya}

Department of Biochemistry, Sher-e-Bangla Agricultural University, Dhaka, Bangladesh. debu@sau.edu.bd

\begin{abstract}
Objective: To evaluate and compare in vitro antioxidant activity of methanol extract of the indigenous Withania somnifera with the imported root extract.

Methods: $A B T S^{++}$radical cation de-colorization assay, $D P P H^{\circ}$ radical scavenging activity, nitric oxide radical scavenging activity, $\mathrm{Fe}^{2+}$ chelating activity assay, superoxide anion and hydrogen peroxide radical scavenging activity and ferrous reducing power were studied.
\end{abstract}

Results: The indigenous root extracts was observed comparatively better antioxidant activity than the imported root extract.

Conclusion: Indigenous root extract showed high antioxidant potential compared to the imported root extract. Present study of antioxidant activities of Withania somnifera root is the first ever report in Bangladesh.

Keywords: Withania somnifera, Solanaceae, Folk medicine, Antioxidant, In vitro.

\section{INTRODUCTION}

The use of herbal medicine and herbal medicinal products both in developing and developed countries are increasing day by day due to their origin and less side effects. There are many sources of traditional medicines. These may be medicinal plants, minerals and organic and inorganic matter [1]. Traditional herbal medicines are new therapeutic candidates because of their, structural complexity, chemical diversity, lack of substantial toxic effects, and broad spectrum of antimicrobial activity [2].

Medicinal plant, Withania somnifera is a small, woody shrub of $60-200 \mathrm{~cm}$ height in the Solanaceae family. Withania somnifera is locally known as Ginseng and Ashwagandha. It can be found in the India, Mediterranean, and Africa. The roots of this plant are mainly used therapeutically [3, 4]. Withanolides, which are the active pharmaceutical ingredients, are isolated from the root and leaves of Withania somnifera. Recently, the plant was found to show antibacterial activities [5, 6 and 7]. Besides antibacterial activities it also shows immune modulatory and antitumor activity [8,9 and 10]. Sehgal, 2012 described that root extract of Withania somnifera can reverse Alzheimer's disease 
pathology via the peripheral clearance of $\beta$-amyloid [11]. Kataria et. al. was found that the water extract from the leaves of Withania somnifera protect RA differentiated $\mathrm{C}_{6}$ and IMR-32 cells against glutamate-induced excitotoxicity [12].

Ashwagandha was found to have anti-carcinogenic effects. Research on animal cell cultures has revealed that the herb reduces the intercellular tumor necrosis factor, decreases the levels of the nuclear factor kappa B and potentiates apoptotic signaling in cancerous cell lines [13]. Ashwagandha also has capacity to fight cancers by reducing tumor size $[\mathbf{1 4}, \mathbf{1 5}]$.

The reactive oxygen species (ROS) such as hydroxyl, hydrogen peroxide, superoxide, nitric oxide radical are continuously being produced during regular physiological processes. These reactive radicals may cause cellular injuries, damage bio-molecules such as carbohydrates, nucleic acids, proteins, poly unsaturated fatty acids and lipids, eventually resulting in cancer, cardiovascular diseases, and diabetes. Previous researches conducted on Withania species revealed the presence of steroidal lactones, alkaloids, flavonoids, tannin. However, to date no studies have been reported on the locally grown indigenous Withania somnifera. Therefore, our aim was to evaluate the antioxidant potential of the Withania somnifera and to compare it with the imported root extract.

\section{Material AND Methods}

\subsection{Collection of the Plant Samples}

The experiment was carried out on two kinds of Withania somnifera root samples, one is Withania Somnifera Indigenous (WSI) and other is Withania Somnifera Foreign (WSF). WSI and WSF were collected from Rajsashi District, Bangladesh and kolkata, India respectively during winter season. The specimens were identified and authenticated by Taxonomist, Bangladesh National Herbarium, Sector2, Mirpur, Dhaka-1216, Bangladesh

\subsection{Chemicals}

All the chemicals used as methanol, petroleum ether, sodium carbonate, aluminium chloride, ferrous chloride, ferric chloride, disodium hydrogen phosphate dodeca hydrate, potassium persulfate, sodium dihydrogen phosphate dehydrate, Ethylenediaminetetraacetic acid (EDTA), potassium ferricyanide, gallic acid, Folin's-Ciocalteu reagentquercetin, L-ascorbic acid, 2, 2-Diphenyl-1-Picryl Hydrazyl (DPPH), trichloroacetic acid (TCA), ferrozine, sodium nitroprusside, citric acid, sulfanilamide, $o$ phosphoric acid, naphthyl ethylenediamine dihydrochloride, 2, 2'-Azinobis-3-ethylbenzothiozoline-6sulfonic acid (ABTS), phenazine methosulphate, ferrous chloride tetrahydrate, nitro blue tetrazolium (NBT) and hydrogen peroxide were collected from Merck (Germany).

\subsection{Extract Preparation}

The collected roots of Withania Somnifera were washed in water, dried in open air for 2-3 weeks at $35-40{ }^{\circ} \mathrm{C}$ temperature. Those dried materials were pulverized in an electric grinder. $100 \mathrm{~g}$ dry powders were defatted with petroleum ether and successively extracted with methanol $\left(64-66^{\circ} \mathrm{C}\right)$. Finally, $12.0 \mathrm{~g}$ defatted dry extract was obtained.

\subsection{Phytochemical Screening}

Phytochemical screening of defatted methanolic extract of Withania somnifera was carried out according to the method used by Mbaebie et al., 2012 [16].

\subsubsection{Estimation of Total Phenolic Content}

Total phenolic content of the methanolic extracts of the root of Withania somnifera was determined using gallic acid equivalence (GAE) [17]. The dry extracts were diluted with methanol to obtain a concentration of $1 \mathrm{mg} / \mathrm{ml}$. $0.5 \mathrm{ml}$ of each sample was transferred to a $10 \mathrm{ml}$ volumetric flask, to which $5 \mathrm{ml}$ undiluted Folin's-Ciocalteu reagent was added. After one minute, $4 \mathrm{ml}$ of $7.5 \%$ (w/v) $\mathrm{Na}_{2} \mathrm{CO}_{3}$ was added, and the volume was made up to $10 \mathrm{ml}$ with distilled water. The reaction mixture was incubated at $40{ }^{\circ} \mathrm{C}$ for half an hour; the absorbance of solution was measured at $765 \mathrm{~nm}$ by UVVisible spectrophotometer (Model: UV-1800, Shimadzu Corporation, Japan) and compared with a pre-prepared gallic acid calibration curve. The end point of reaction mixture was indicated by the formation of blue color in the solution. 


\subsubsection{Determination of Total Flavonoid Content}

Total flavonoid content of the methanolic extracts of Withania somnifera root was assessed by the method followed by Velusamy and Veerabahu, $2012[\mathbf{1 8}] .0 .5 \mathrm{ml}$ of extract $(1: 10 \mathrm{~g} / \mathrm{ml})$ was mixed with ethanolic solution of $\mathrm{AlCl}_{3}(10 \%, 0.1 \mathrm{ml})$ and potassium acetate $(0.1 \mathrm{ml}$ of $1 \mathrm{M})$. After half hour incubation at room temperature, a yellow color indicated the presence of flavonoid. The absorbance was measured at $415 \mathrm{~nm}$. The total flavonoid content was calculated as quercetin equivalent (mg QE/g).

\subsubsection{DPPH Radical Scavenging Activity}

The ability of Withania somnifera extracts to scavenge DPPH radical was assessed by using the method of Shih et al., 2010 with modification [19]. Briefly, the aliquots of the extract with varying concentrations (ranging from $20-100 \mu \mathrm{g} / \mathrm{ml}$ ) were mixed with $2.0 \mathrm{ml}$ DPPH $(0.1 \mathrm{mmol} / \mathrm{L}$ in methanol). After 30 minute incubation at $37^{\circ} \mathrm{C}$ the absorbance was recorded at $517 \mathrm{~nm}$ with the UV-Visible spectrophotometer. The following formula was used to determine the percentage of scavenging activity,

Percentage of inhibition $(\%)=\left[\left(\mathrm{A}_{\text {control }}-\mathrm{A}_{\text {sample }}\right) / \mathrm{A}_{\text {control }}\right] \times 100$

Where, $\mathrm{A}_{\text {control-absorbance of DPPH, }}$

$\mathrm{A}_{\text {sample}}$-absorbance reaction of mixture (DPPH with Sample)

\subsubsection{Ferric Reducing Power}

The reducing ability of Withania somnifera methanolic extracts was measured according to the method of Singh et al., 2009 [20]. Methanolic extracts (1.0 ml) of varying concentrations (20-100 $\mu \mathrm{g} / \mathrm{ml})$ were mixed with $2.5 \mathrm{ml}$ of phosphate buffer $(0.2 \mathrm{M}, \mathrm{pH} 6.6)$ and $2.5 \mathrm{ml}$ of potassium ferricyanide $(1 \%)$. The mixture was incubated at $50{ }^{\circ} \mathrm{C}$ for 20 minutes with TCA $(10 \%: 2.5 \mathrm{ml})$. Then the mixture was centrifuged at $3000 \mathrm{rpm}$ for 10 minutes. The supernatant $(2.5 \mathrm{ml})$ was mixed with $2.5 \mathrm{ml}$ of distilled water and $0.5 \mathrm{ml}$ of ferric chloride $(1 \%)$. The absorbance of the reaction mixture was measured at $700 \mathrm{~nm}$ by using the UV-Visible spectrophotometer. The higher absorbance of the reaction mixture indicated greater reducing power. The reducing power of methanolic extract of Withania somnifera was compared with that of standard antioxidant $L$-ascorbic acid $(1000 \mu \mathrm{g} / \mathrm{ml})$.

\subsection{5. $\mathrm{Fe}^{2+}$ Chelating Activity Assay}

The chelating activity of Withania somnifera root extracts was evaluated by measuring the $\mathrm{Fe}^{2+}$ chelating activity according to the method of Thambiraj et al., 2012 [21]. Aliquots of extracts at various concentrations $(20-100 \mu \mathrm{g} / \mathrm{ml})$ were added to $0.1 \mathrm{ml}$ of $\mathrm{FeCl}_{2}(2 \mathrm{mM})$ in $1.6 \mathrm{ml}$ of distilled water. After $30 \mathrm{~s}, 0.2 \mathrm{ml}$ of ferrozine solution $(5 \mathrm{mM})$ was added to the solution. The reaction mixture was incubated for 10 minutes at $30{ }^{\circ} \mathrm{C}$ and the absorbance of the $\mathrm{Fe}^{2+}$ ferrozine complex was measured at $562 \mathrm{~nm}$. A lower absorbance indicates a higher chelating power. The chelating activity of the extracts on $\mathrm{Fe}^{2+}$ was compared with that of EDTA $(0.01 \mathrm{mM})$ and citric acid $(0.025 \mathrm{M})$. The percentage of chelating activity was calculated using the following formula:

Chelating Activity $(\%)=\left(\mathrm{A}_{1}-\mathrm{A}_{2}\right) / \mathrm{A}_{1} \times 100$

Where, $A_{1}$ - absorbance of the reaction mixture without extract,

$\mathrm{A}_{2}-$ absorbance of the reaction mixture with extract

\subsubsection{Nitric Oxide Radical Scavenging Activity}

Nitric oxide radical scavenging activity measurement was carried by the method of Olabinri et al., 2010 [22]. Sodium nitroprusside solution was used to produce nitric oxide radicals. $1 \mathrm{ml}$ of $10 \mathrm{mM}$ sodium nitroprusside solution was mixed with $1 \mathrm{ml}$ of methanolic extract of Withania somnifera aliquot of the extract of different concentrations $(20-100 \mu \mathrm{g} / \mathrm{ml})$ in phosphate buffer $(0.2 \mathrm{M} \mathrm{pH} 7.4)$. The mixture was incubated at $30{ }^{\circ} \mathrm{C}$ for 160 minute. After incubation the reaction mixture was mixed with $1.0 \mathrm{ml}$ of pre-prepared Griessreagent (1\% sulphanilamide, $0.1 \%$ napthylethylenediamine dichloride, and $2 \%$ phosphoric acid). The absorbance was measured at $546 \mathrm{~nm}$ and the percentage of inhibition was calculated utilizing the formula no.1. A decrease in the absorbance indicates a high nitric oxide scavenging activity. 


\subsubsection{ABTS $^{\cdot+}$ Radical Cation Decolourisation Assay}

The Withania somnifera extracts were evaluated for their $\mathrm{ABTS}^{{ }^{++}}$radical capacity following a method used by Ramesh and Sivasudha, 2012 [23]. The experiments were carried out using an improved ABTS decolorization method. $\mathrm{ABTS}^{\circ+}$ was generated by oxidation of $\mathrm{ABTS}^{\circ+}$ with potassium persulfate. $2 \mathrm{ml}$ of generated $\mathrm{ABTS}^{\circ+}$ solution was mixed with $20 \mathrm{ml}$ of methanol extract solution of different concentrations $(20-100 \mu \mathrm{g} / \mathrm{ml})$. The decreasing absorption was measured after 6 min interval at $734 \mathrm{~nm}$. The inhibition of the $\mathrm{ABTS}^{\circ+}$ radical scavenging activity was calculated using the formula no. 1.

\subsubsection{Superoxide Anion Scavenging Activity}

Superoxide anion scavenging activity was assessed according to the method of Ilhami et al., 2005 [24]. The reaction mixture consisted of various concentrations $(20-100 \mu \mathrm{g} / \mathrm{ml})$ of Withania somnifera root extracts $(1 \mathrm{ml}$ in methanol), $1 \mathrm{ml}$ of phenazine methosulphate (PMS) solution $(60 \mu \mathrm{M}$ PMS in phosphate buffer $0.1 \mathrm{M}$ ) and $1 \mathrm{ml}$ of nitro blue tetrazolium (NBT) solution (150 $\mu \mathrm{M}$ NBT in phosphate buffer $0.1 \mathrm{M}$ ) was prepared to initiate the reaction. The reaction mixture was incubated at $27{ }^{\circ} \mathrm{C}$ for 10 minute, and the absorbance was measured at $560 \mathrm{~nm}$. L-ascorbic acid was used as standard. Formula no. 1 was used to calculate the ability to scavenge the superoxide radicals and the percentage inhibition.

\subsubsection{Hydrogen Peroxide Radical Scavenging Activity}

The hydrogen peroxide radical scavenging activity was assessed by utilizing the method used by Mohammad and Ali, 2010 [25]. Methanolic extract of Withania somnifera root aliquots of concentrations ranging $20-100 \mu \mathrm{g} / \mathrm{ml}$ were added to $0.6 \mathrm{ml}$ hydrogen peroxide $(40 \mathrm{mM})$ solution in already prepared phosphate buffer $(\mathrm{pH} 7.4)$. The reaction mixtures were then incubated for 15 minutes at room temperature. After incubation, the reaction mixture absorbance reading at $230 \mathrm{~nm}$ against phosphate buffer was taken as blank. The percentage of inhibition calculated based on the formula no. 1 as:

Inhibition $(\%)=\left(\mathrm{A}_{1}-\mathrm{A}_{2}\right) / \mathrm{A}_{1} \times 100$

Where, $\mathrm{A}_{1}$-absorbance of the $\mathrm{H}_{2} \mathrm{O}_{2}$

$\mathrm{A}_{2}-$ absorbance of the reaction mixture with extract

\subsection{Statistical Analysis}

All experiments were repeated at least thrice. The results were expressed with the mean \pm standard deviation.

\section{RESULTS}

\subsection{Phytochemical Screening of Withania Somnifera}

The defatted methanolic extract of Withania somnifera root contains tannins, terpenoids, flavonoids, alkaloids, cardio glycosides, steroids, amino acids and proteins (Table-1).

Table1. Phytochemical screening of the Withania somnifera

\begin{tabular}{|c|c|c|c|c|c|c|c|c|c|}
\hline \multirow{2}{*}{ Extracts } & \multicolumn{10}{|c|}{ Major secondary metabolites present } \\
\cline { 2 - 19 } & AL & SA & TER & FLA & S & G & T & AA & P \\
\hline Indigenous root & ++ & +++ & - & +++ & + & ++ & ++ & ++ & ++ \\
\hline Imported root & + & +++ & - & ++ & - & + & + & ++ & ++ \\
\hline
\end{tabular}

Alkaloids - AL, Saponins-SA, Terpenoids-TER, Flavonoids - FLA, Steroids - S, Glycosides -G, Tannins - T, Amino acids $-A A$ and Protein $-P$

Note: (+) Present in low concentration, (++) Present in medium concentration, (+++) Present in high concentration, (-) Not present.

\subsection{Estimation of Total Phenolic Content}

The data oftotal phenolic content in methanolic extract of Withania somnifera root was depicted in Figure 1. The Gallic acid linear curve obtained using $Y=6.9104 \mathrm{X}-0.0937,\left(\mathrm{R}^{2}=0.9972\right)$. Using this gallic acid linear curve, total phenolic content values of Withania somnifera indigenous root and imported root were found to be $0.52 \mathrm{mg} / \mathrm{ml}$ and $0.39 \mathrm{mg} / \mathrm{ml}$ respectively. The total phenolic content was high in indigenous root extract compared to the imported root extract. It shows the Withania somnifera indigenous root possesses high antioxidant ability. 


\subsection{Determination of Total Flavonoid Content}

The total flavonoid $(\mathrm{mg} / \mathrm{ml})$ content was obtained using the regression calibration curve $\mathrm{Y}=6.9104 \mathrm{X}$ 0.0937, $\left(R^{2}=0.9972\right)$ (Figure 2) with quercetin equivalent. For the indigenous Withania somnifera root extract, the value of total flavonoid content was found to be $0.50 \mathrm{mg} / \mathrm{mL}$, which is comparatively higher than that found for imported root with a value of $0.38 \mathrm{mg} / \mathrm{mL}$.

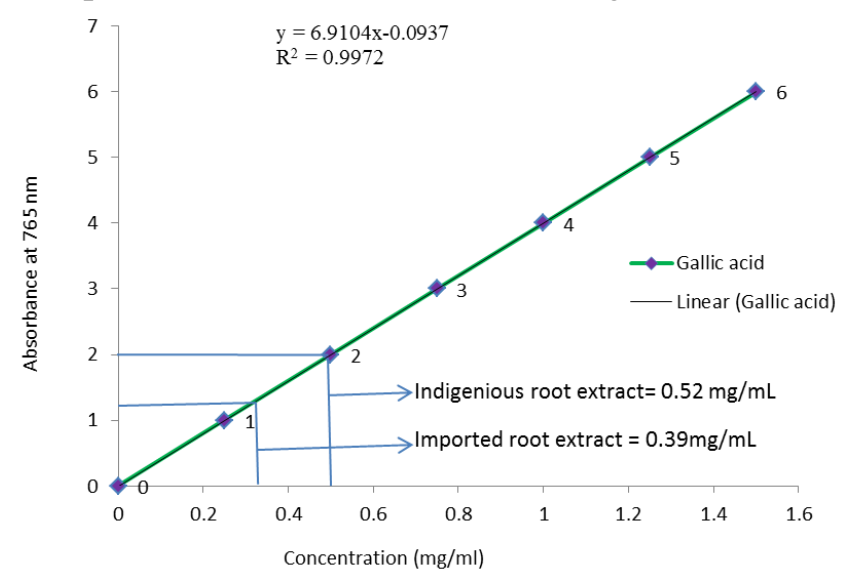

Figure 1. Total phenolic content

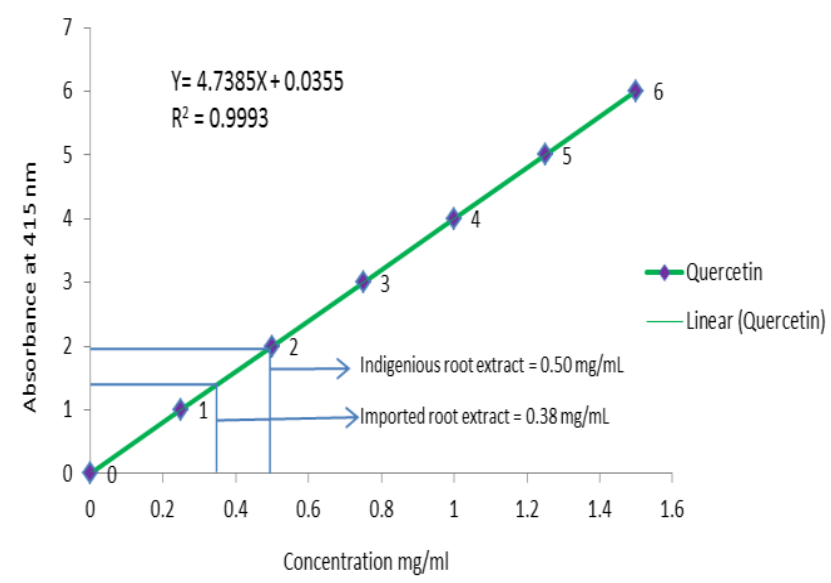

Figure 2. Total flavonoid content

\subsection{DPPH` Radical Scavenging Activity}

The photometric evaluation of the antioxidant capacity of the methanolic extracts of Withania somnifera indigenous (WSI) root and imported (WSF) root showed good antioxidant capacity (Figure 3). Significant decrease was observed in the DPPH radical activity due to the scavenging ability of the extracts. The $\mathrm{IC}_{50}$ values of the methanolic extract of Withania somnifera imported (WSF) root, indigenous (WSI) root and standard antioxidant (ascorbic acid) were found as $18 \mu \mathrm{g} / \mathrm{mL}, 12 \mu \mathrm{g} / \mathrm{mL}$ and $10 \mu \mathrm{g} / \mathrm{mL}$ respectively. A lower $\mathrm{IC}_{50}$ value indicates a higher free radical scavenging activity [26]. The ability of DPPH radical scavenging is higher in indigenous (WSI) root extract compare to the imported (WSF) root extract.

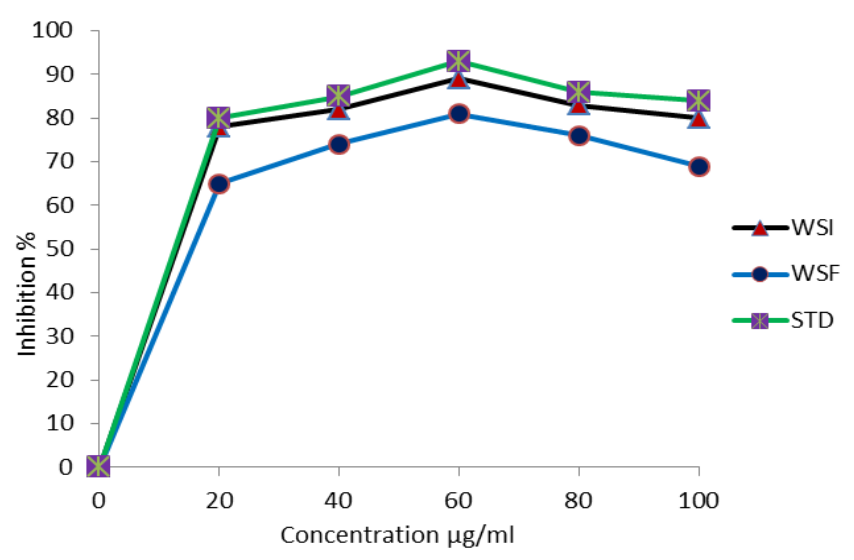

Figure 3. DPPH radical scavenging activity 


\subsection{Ferric Reducing Power}

The reducing ability for both of the root extracts (WSI and WSF) was found to increase with increasing concentration of the sample. The higher absorbance value indicates a high antioxidant capacity of the extracts [27]. The result showed a higher value of absorbance for WSI root extract compared to the WSF root implying that the extracts possess ferric ions $\left(\mathrm{Fe}^{3+}\right)$ reducing ability (Figure 4).

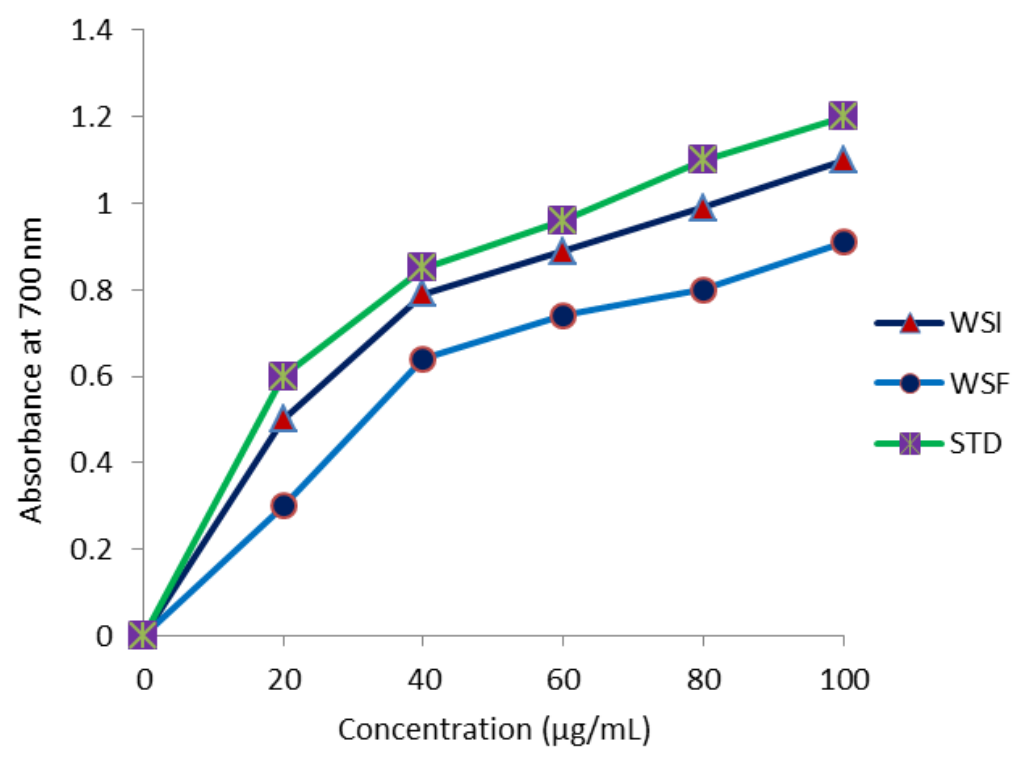

Figure 4. Ferric reducing power

\section{6. $\mathrm{Fe}^{2+}$ Chelating Activity Assay}

The $\mathrm{Fe}^{2+}$ chelating activity assessment revealed that the root extracts show potent chelating power. The $\mathrm{IC}_{50}$ values were $18 \mu \mathrm{g} / \mathrm{ml}$ for WSI root, $21 \mu \mathrm{g} / \mathrm{ml}$ for WSF root and $17 \mu \mathrm{g} / \mathrm{ml}$ for standard $L$ ascorbic acid (Figure 5). The iron generates free radicals through the Haber-Weiss and the Fenton reactions responsible for the oxidative stresses in biological systems.

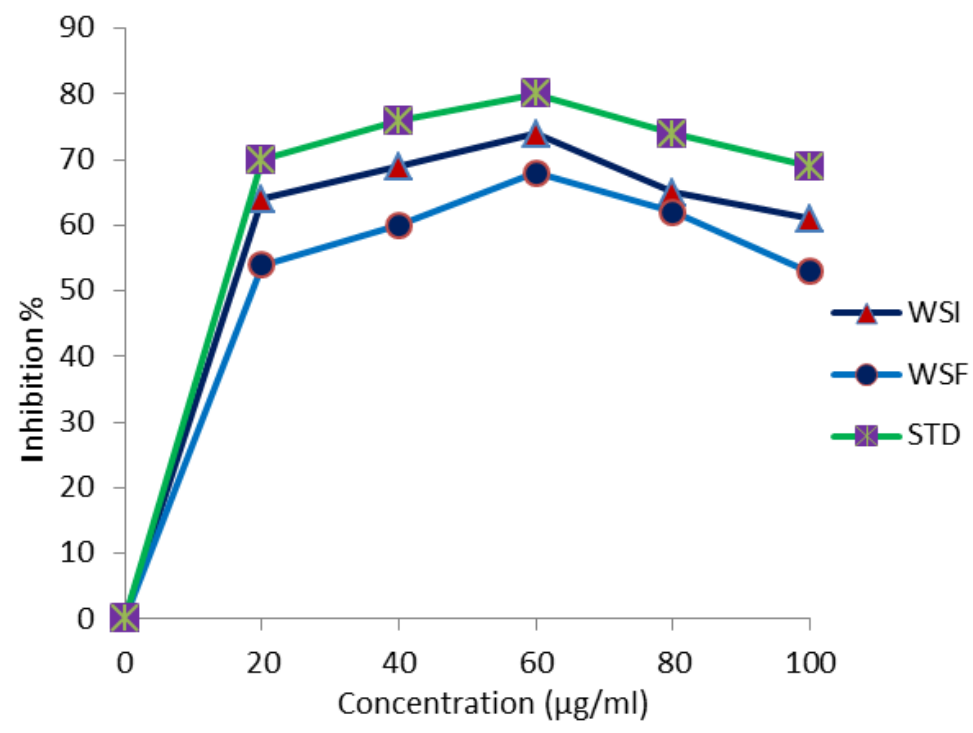

Figure 5. $\mathrm{Fe}^{2+}$ chelating activity

\subsection{Nitric Oxide Radical Scavenging Activity}

Nitric oxide radical scavenging activity estimation of Withania somnifera root extracts was performed by formation of nitric oxide using sodium nitroprusside. Sodium nitroprusside acts as major source of nitric oxide radicals. The extracts scavenge the nitric oxide formed from the sodium nitroprusside by inhibiting the chromophore formation, hence absorbance decreases with increasing the concentrations of the extracts [28]. The $\mathrm{IC}_{50}$ values were $27 \mu \mathrm{g} / \mathrm{ml}$ in WSI root, $55 \mu \mathrm{g} / \mathrm{ml}$ in WSF root (Figure 6) revealed that, WSI is more potent NO radical scavenger compared to its counterpart WSF. 


\subsection{ABTS•+ Radical Cation Decolourisation Assay}

The $\mathrm{ABTS}^{++}$radical scavenging ability was found to be higher in Withania somnifera indigenous (WSI) root extract compared to the Withania somnifera imported (WSF) root extract. The $\mathrm{IC}_{50}$ values were found to 20,18 and $16 \mu \mathrm{g} / \mathrm{ml}$ in WSF root, WSI root and $L$-ascorbic acid standard respectively (Figure 7).

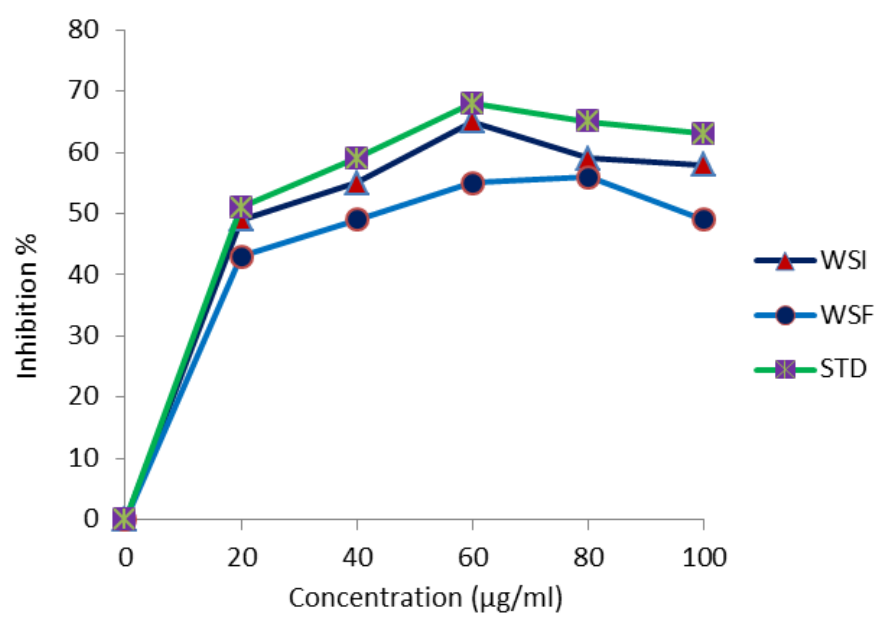

Figure 6. Nitric oxide radical scavenging activity

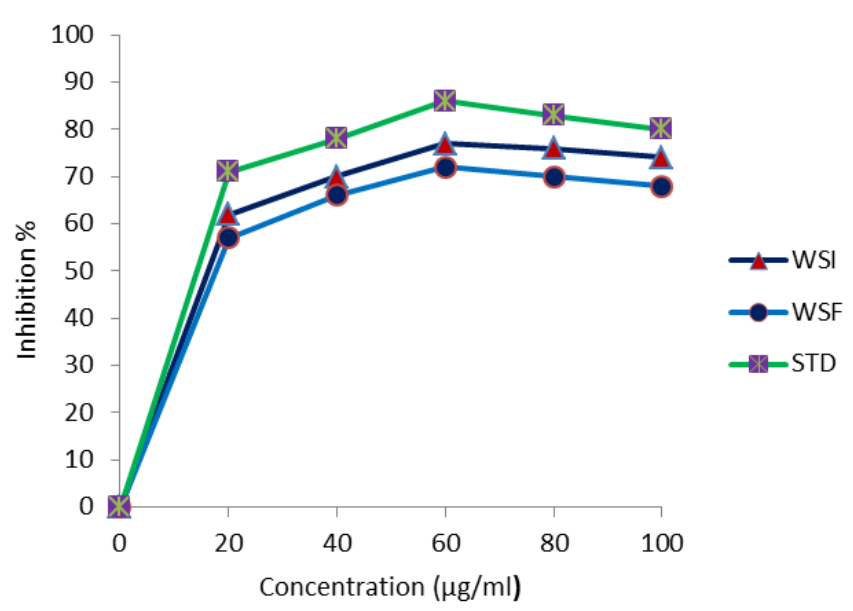

Figure 7. ABTS radical cation decolourisation assay

\subsection{Superoxide Anion Scavenging Activity}

The phenomenon of reduction of the yellow dye $\left(\mathrm{NBT}^{2+}\right)$ to produce the blue formazan was utilized to determine the superoxide scavenging activity of the root. The Withania somnifera imported (WSF) and Withania somnifera indigenous (WSI) root extracts have potent antioxidants capacity. The decrease in absorbance at $560 \mathrm{~nm}$ indicates the high antioxidant power and the $\mathrm{IC}_{50}$ values of WSF root and WSI root were found to be $30 \mu \mathrm{g} / \mathrm{ml}$ and $19 \mu \mathrm{g} / \mathrm{ml}$ respectively (Figure 8).

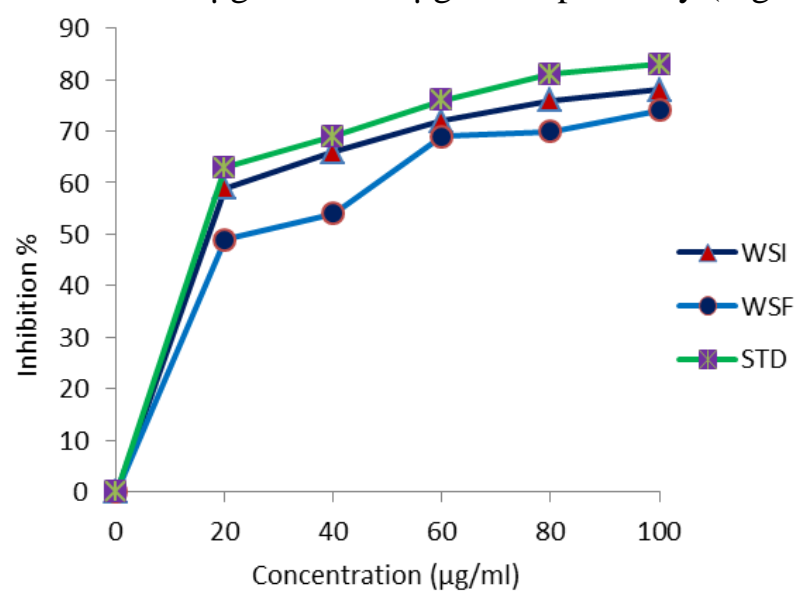

Figure 8. Superoxide anion scavenging activity 


\subsection{Hydrogen Peroxide Radical Scavenging Activity}

Hydrogen peroxide scavenging abilities of the Withania somnifera imported (WSF) root and Withania somnifera indigenous (WSI) root extracts are shown in Figure 9. L-ascorbic acid was used as standard antioxidant and found the $\mathrm{IC}_{50}$ value to be $36 \mu \mathrm{g} / \mathrm{ml}$. The Withania somnifera indigenous (WSI) root possesses higher scavenging activity compared to the Withania somnifera imported (WSF) root and $\mathrm{IC}_{50}$ values were calculated to be $64 \mu \mathrm{g} / \mathrm{ml}$ and $94 \mu \mathrm{g} / \mathrm{ml}$ respectively.

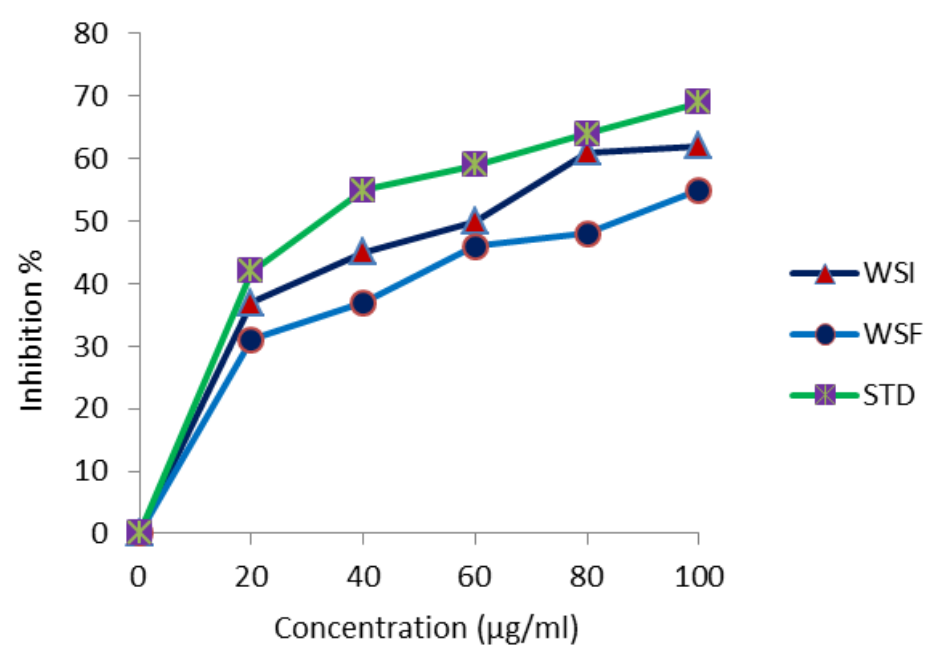

Figure 9. Hydrogen peroxide radical scavenging activity

\section{DISCUSSION}

The free radicals are very unstable chemical species containing one or more unpaired electrons that causes damage to other molecules by removing electrons from them with a specific end goal to achieve stability. Free radicals assume the double part as both pernicious and valuable species since they can be either harmful or beneficial to the living system. It is apparent from this study, that Withania somnifera root extract possesses effective antioxidant activity. In vitro antioxidant assay of the methanolic extract of Withania somnifera root was explored in the present study by total flavonoid content, total phenolic content, nitric oxide radical, $\mathrm{DPPH}^{\circ}$ radical, hydrogen peroxide radical and superoxide anion scavenging activities, $\mathrm{ABTS}^{\circ+}$ radical cation de-colourisation, $\mathrm{Fe}^{2+}$ chelating activity assay and ferric reducing power. The antioxidant activities of plant extracts can be ascribed to the presence of respective phytochemicals like phenolics, flavonoids, alkaloids, saponins, steroids, glycosides, tannins, protein and amino acids in that species $[\mathbf{2 9}, \mathbf{3 0}]$. Reactive oxygen species (ROS) readily combine and oxidize biomolecules thus making them inactive subsequently causing damage to cells, tissues and organs. Antioxidants mainly work by neutralizing the free radicals produced in the biological systems [31, 32].

Higher phenolic contents such as flavonoids, polyphenols and mono-phenols are some features of medicinal plants [33]. The flavonoid and phenolic compounds are responsible for the antioxidant ability of the medicinal plants [34] and these are abundant in some vegetables, fruits and flowers [35]. Antioxidants, derived from plant origin, especially flavonoids and polyphenols have been used to treat various disease such as aging, diabetic, cancer and prevention of cardiovascular diseases.

In contrast to imported (WSF) root, indigenous (WSI) root contains more phenolic and flavonoid contents. Periyar et al., 2012, recently, found the lower level of total flavonoid and phenolic contents in the polished Erythrina indica root of India [36]. On the other hand, Srikanth et al., 2012, found similar values for both contents in Indigofera cassioides Rottl. Ex. DC. leaf of India [37]. Sridevi et al., 2013, also found comparatively higher levels of the phenolic compound in the Solanum surattense leaf of india [38].

The $\mathrm{DPPH}^{\circ}$, a stable free radical, is destroyed by a free radical scavenger, as the scavenger accepts an electron or hydrogen radical to become a stable diamagnetic molecule [39]. From the result, a dosedependent relationship on the $\mathrm{DPPH}^{\bullet}$ radical scavenging activity can be observed. It has been found that, glutathione, cysteine, tocopherols, ascorbic acid, tannins, flavonoids and aromatic amines reduce and decolorize the $\mathrm{DPPH}^{\circ}$ by their hydrogen donating ability since they produce hydrazine by producing paired electrons [40]. Flavonoids and phenolic compounds of methanolic extracts of both 
indigenous and imported Withania somnifera root are possibly involved in this antiradical activity [41]. Our finding of the present work is supported by the observation of $\mathrm{DPPH}^{*}$ scavenging activity of Indigofera cassioides Rottl. Ex. DC. leaf by Srikanth et al., 2012 [37].

The reducing power of the extract was explored by the transformation of $\mathrm{Fe}^{3+}$ to $\mathrm{Fe}^{2+}$ through the electron transfering ability that serves as a significant indicator of its antioxidant activity. The reductive activity of the extract and the standard increased with increasing concentration. The antioxidant activity of Withania somnifera root extract was slightly lower than that of the standard used in this present study. Findings from this study showed that the antioxidant activity is well advocated by the observation of the antioxidant activity of Schotia latifolia bark extract by Mbaebie $e t$ al., 2012 [16].

Stable Iron chelation formation was utilized to evaluate the chelating ability of the extracts. The high chelating power by ferrozine reduces the free ferrous ion concentration resulting in the decrease in the Fenton reaction which is implicated in many diseases [42]. The extracts showed significant metal ion scavenging effect with an increasing trend with the increase in the concentrations of the extracts. The methanolic root extracts of Withania somnifera were found to possess higher metal ion scavenging activity than that of the standard. It may be due to the formation of sigma bonds with the metal and effective as secondary antioxidants because they reduce the redox potential [43]. Similar trend of metal ion scavenging activity was observed in the species Leucas indica var nagalapuram lana and Leucas indica var lavandulifolia [44].

The nitric oxide plays a pivotal role in human body, particularly in various types of inflammatory processes [40] physiological process and also has its fair share of importance as the chemical mediator in endothelial cells, macrophages, neurons [40]. However, nitric oxide in excess concentration can cause several diseases. Nitrate and peroxynitrite anions are generated when excess nitric oxide reacts with oxygen [45]. The free radical scavengers in the extract compete with oxygen leading to the decrease in the concentration of nitrite ion. Both the extracts e.g. indigenous (WSI) root and imported (WSF) root have shown good ability to scavenge nitric oxide. Vijayabaskar and Shiyamala, 2012 have reported similar tendency in nitric oxide scavenging activities by Turbinaria ornate extract [46].

ABTS ${ }^{*}$ radical is often used for the screening of complex antioxidant mixtures such as beverages, biological fluids and plant extracts for their antioxidant activities because of its ability in both the organic and aqueous media and the stability in a wide $\mathrm{pH}$ range [47]. The extract showed potent antioxidant activity in ABTS method which is consistent with that reported by, Srikanth et al., 2012 and is comparable with the standard used [37]. Here, the extract's radical scavenging activity is for the direct role of its phenolic compounds in free radical scavenging.

Superoxide is produced by the oxidative enzyme of a body from molecular oxygen through nonenzymatic reaction. The superoxide generates too much harmful oxygen species in a human body such as singlet oxygen and hydroxyl radicals and these may cause the peroxidation of lipids [48].

Final result of superoxide anions in the body may be the reaction with biological macromolecules leading to tissue damage [49]. The extracts were found to be efficient scavengers of superoxide radical. Raja et al., 2012 has reported similar tendency in superoxide scavenging activities by Phyllanthus acidus leaf extracts [49]. These results and literature survey clearly indicate that the indigenous Withania somnifera root extract has a noticeably higher superoxide scavenging activity compared to that of the imported one.

The presence of $\mathrm{H}_{2} \mathrm{O}_{2}$ in the cell culture may lead to DNA oxidative damage. Hence removal of hydrogen peroxide is very essential for antioxidant defense in cells. Ramalingam et al., 2012 reported in a recent report that the methanolic extract of Withania somnifera root shows high degree of $\mathrm{H}_{2} \mathrm{O}_{2}$ scavenging activity [44]. In our present study we observed that the Withania somnifera indigenous (WSI) root extract possesses higher scavenging activity compared to the imported one (WSF).

\section{Conclusion}

Antioxidant activity was correlated with the $\mathrm{ABTS}^{\circ+}$ radical cation de-colorization assay, DPPH radical scavenging activity, ferrous reducing power, nitric oxide radical scavenging activity, $\mathrm{Fe}^{2+}$ chelating activity assay, superoxide anion and hydrogen peroxide radical scavenging activities. The data obtained from these studies were high in indigenous root compared to the imported root extracts which indicate Withania somnifera indigeneous root show higher antioxidant activity. So the isolation 
of bioactive compounds from Withania somnifera will definitely serve as a good phytotherapeutic agent.

\section{CONFLiCT OF INTEREST STATEMENT}

We declare that we have no conflict of interest.

\section{ACKNOWLEDGEMENT}

We gratefully acknowledge Department of Chemistry, Bangladesh University of Engineering and Technology (BUET), Dhaka-1000, Bangladesh and Atomic Energy Research Establishment, Bangladesh Atomic Energy Commission, Dhaka, Bangladesh for their kind cooperation and help to record different instrumental data during this research work.

\section{REFERENCES}

[1] Modak M., Dixit P., Londhe J., Ghaskadbi S., and Devasagayam T.P.A., Indian herbs and herbal drugs used for the treatment of diabetes, Journal of Clinical Biochemistry and Nutrition. 40(3), 163-173 (2007).

[2] Mukhtar M., Rshad M., Ahmad M., Pomerantz R.J., Wigdahl B., and Parveen Z., Anti viral potentials of medicinal plants, Virus Research. 131(2), 111-120 (2008).

[3] Girdhari L., and Rana A., Withania somnifera (Ashwagandha): a review, Pharmacognosy Reviews. (1), 129-136 (2007).

[4] Fawzy T.K.H., Medicinal Plants in Libya, Arab Encyclopedia House, Hazmieh, Lebanon, $1^{\text {st }}$ edition. (1983).

[5] Arora S., Dhillon S., Rani G., and Nagpal A., The in vitro antibacterial/synergistic activities of Withania somnifera extracts, Fitoterapia. 75(3-4), 385-388 (2004).

[6] Owais M., Sharad K.S., Shehbaz A., and Saleemuddin M., Antibacterial efficacy of Withania somnifera(Ashwagandha) an indigenous medicinal plant against experimental murine salmonellosis, Phytomedicine. 12(3), 229-235 (2005).

[7] Teixeira S.T., Valadares M.C., Goncalves S.A., de Melo A., and Queiroz M.L.S., Prophylactic administration of Withania somnifera extract increases host resistance in Listeria monocytogenes infected mice, International Immunopharmacology. 6(10), 1535-1542 (2006).

[8] Ziauddin M., Phansalkar N., Patki P., Diwanay S., and Patwardhan B., Studies on the immunomodulatory effects of Ashwagandha, Journal of Ethnopharmacology. 50(2) 69-76 (1996).

[9] Dhuley J.N., Effect of some Indian herbs on macrophage functions in ochratoxin A treated mice, Journal of Ethnopharmacology. 58(1), 15-20 (1997).

[10] Davis L. and Kuttan G., Immunomodulatory activity of Withania somnifera, Journal of Ethnopharmacology. 71(1-2), 193-200 (2000).

[11] Sehgal, N. Withania somnifera reverses Alzheimer's disease pathology by enhancing lowdensity lipoprotein receptor-related protein in liver, Proc Natl Acad Sci of USA. 109, 3510-3515 (2012).

[12] Kataria H., Wadhwa Renu., Sunil C. and Kaul G.K., Water extract from the leaves of Withania somnifera protect RA differentiated $\mathrm{C}_{6}$ and IMR-32 cells against glutamate-induced excitotoxicity, PLoS ONE. 7(5), 7080(2012).

[13] Ichikawa H., Takada Y., Shishodia S., Jayaprakasam B., Nair M.G., and Aggarwal B.B. "Withanolides potentiate apoptosis, inhibit invasion, and abolish osteoclastogenesis through suppression of nuclear factor-kappa B (NF-Kappa B) activation and NF-Kappa B-regulated gene expression", Molecular Cancer Therapeutics. 5(6), 1434-45 (2006).

[14] Prakash J., Gupta S.K., and Dinda A.K., Withania somnifera root extract prevents DMBAinduced squamous cell carcinoma of skin in Swiss albino mice, Nutr Cancer. 42, 91-97 (2002).

[15] Jayaprakasam B., Zhang Y., Seeram N., and Nair M., Growth inhibition of human tumor cell lines by withanolides from Withania somnifera leaves, Life Sci. 74, 125-132 (2003).

[16] Mbaebie B.O., Edeoga H.O., and Afolayan A.J., Phytochemical analysis and antioxidants activities of aqueous stem bark extract of Schotia latifolia Jacq, Asian Pac J Trop Biomed. 2(2), 118-124 (2012). 
[17] Koncić M.Z., Kremer D., Gruz J., Strnad M., Bisevac G., and Kosalec I., Antioxidant and antimicrobial properties of Moltkia petraea (tratt.) Griseb. flower, leaf and stem infusions, Food Chem Toxicol. 48(6), 1537-1542 (2010).

[18] Velusamy K., and Veerabahu R.M., In vitro antioxidant studies of Begonia malabarica Lam. and Begonia floccifera Bedd, Asian Pac J Trop Biomed. 2, 1572-1577 (2012).

[19] Shih C.L., Jau T.L., Chin K.W., Hsin Y.C., and Deng J.Y., Antioxidant properties of various solvent extracts from lychee (Litchi chinenesis Sonn.) flowers, Food Chemistry, 114, 577-581 (2010).

[20] Singh et al., 2009 Singh R., Singh B., Singh S., Kumar N., Kumar S. and Arora S., Investigation of ethyl acetate extract/fractions of Acacia nilotica wild. Ex. Del as potent antioxidant, Rec Nat Prod. 3, 131-138 (2009).

[21] Thambiraj J., and Paulsamy S., In vitro antioxidant potential of methanol extract of the medicinal plant, Acacia caesia (L.) Willd", Asian Pac J Trop Biomed. 2, 732-736 (2012).

[22] Olabinri B.M., Odedire O.O., Olaleye M.T., Adekunle A.S., Ehigie L.O., and Olabinri P.F., In vitro evaluation of hydroxyl and nitric oxide radical scavenging activities of artemether, Research Journal of Biological Science. 5(1), 102-105 (2010).

[23] Ramesh Kumar A., and Sivasudha T., In vitro antioxidant and antibacterial activity of aqueous and methanolic extract of Mollugo nudicaulis Lam Leaves, Asian Pac J Trop Biomed. 2(2), 895900 (2012).

[24] Ilhami G.I., Haci A.A., and Mehmet C., Determination of in vitro antioxidant and radical scavenging activities of propofol, Chem Pharm Bull. 53(3), 281-285 (2005).

[25] Mohammad A.E., and Ali S., Antioxidant, free radical scavenging activities of Salvia brachyantha and its protective effect against cardiac cell injury, Food and Chemical Toxicology. 48, 846-853 (2010).

[26] Ozsoy et al., 2008 Ozsoy N., Can A., Yanardag R., and Akev N., Antioxidant activity of Smilax excelsa L. leaf extracts, Food Chem. 110, 571-583 (2008).

[27] Francis M.A., Peter N.U., Julius O.O., John R., Patrick I., and Xiao-Jian Y., Free radical scavenging activity and immunomodulatory effect of Stachytarpheta angustifolia leaf extract, Food Chem.119(4), 1409-1416 (2010).

[28] Halliwell B., and Gutteridge J.M., Role of free radicals and catalytic metal ions in human disease: an overview, Methods Enzymol.18, 1-85 (1990).

[29] Akter R., Raquibul Hasan S.M., Mokarram Hossain M., Jamila M., Sultana S., Chowdhury Mazumder M.E.H., and Rahman S., Antidiarrhoeal and antioxidant properties of Curcuma alismatifolia leaves, Australian Journal of Basic and Applied Sciences, 4(3), 450-456 (2010).

[30] ArmoskaiteV., Ramanauskiene K., Maruska A., Razukas A., Dagilyte A., Baranauskas A., and Briedis V., The analysis of quality and antioxidant activity of green tea extracts, Journal of Medicinal Plants Research. 5(5), 811-816 (2011).

[31] Siddique A. N., Mujeeb M., Kalam Najmi A., and Akram M., Evaluation of antioxidant activity, quantitative estimation of phenols and flavonoids in different parts of Aeglemarmelos, African Journal of Plant Science. 4(1), 1-5 (2010).

[32] Koksal E., Bursal E., Dikici E., Tozoglu F., and Gulcin I., Antioxidant activity of Melissa officinalis leaves, Journal of Medicinal Plants Research. 5(2), 217-222 (2011).

[33] Zhao-Jian G., Jian-Bing L., and Xing-Guo X., Purification and characterization of polyphenol oxidase from leaves of Cleome gynandra L, Food Chem. 129(3), 1012-1018 (2011).

[34] Sangilimuthu A., Lukmanul H.F., and Sathish K.R., Antioxidant activity of Withania somnifera (L.) Dunal by different solvent extraction methods, J Pharm Res. 4(5), 1428-1430 (2011).

[35] Onanong K., Sirithon S., Natthida W., and Naret M., Phenolic compounds and antioxidant activities of edible flowers from Thailand, J Funct Food. 3, 88-99 (2011).

[36] Periyar R.R.S., Toda S., and Kandasamy M., Phytochemical screening and in-vitro anti-oxidant activity of methanolic root extract of Erythrina indica, Asian Pac J Trop Biomed. 2, 1696-1700 (2012). 
[37] Srikanth G., Manohar B.S., Kavitha C.H.N., Bhanoji Rao M.E., Vijaykumar N., and Pradeep C.H. (2010) Senthil R.K., Rajkapoor B. and Perumal P., Antioxidant activities of Indigofera cassioides Rottl. Ex. DC. Using various in vitro assay models, Asian Pac J Trop Biomed. 2(4), 256-261(2012).

[38] Sridevi M., Senthil S. and Pugalendi K.V. "In vitro antioxidant activities of Solanum surattense leaf extract", Asian Pac J Trop Biomed. 3(1), 28-34 (2013).

[39] Kalaivani T., and Mathew L., Fee radical scavenging activity from leaves of Acacia nilotica (L.) Wild ex Delile, an Indian medicinal tree, Food Chem Toxicol. 48, 298-305 (2010).

[40] Filomena, C., Mariangela, M., Colica, C., Federica, M., Perri, V., and Dimitar, U. "Bioactive phytonutrients (omega fatty acids, tocopherols, polyphenols), in vitro inhibition of nitric oxide production and free radical scavenging activity of non-cultivated Mediterranean vegetables, Food Chem. 129(4), 1413-1419 (2011).

[41] Halliwell B., and Gutteridge J.M.C., Free radicals in biology and medicine, $4^{\text {th }}$ ed. Oxford: Oxford University Press (2007).

[42] Ilhami G., Antioxidant activity of $L$-adrenaline: A structure-activity insight, Chem Biol Interact, 179, 71-80 (2009).

[43] Gulcin I.S., Beydemir H., Alici A., Elmasta M. and Buyukokuroglu M.E., In vitro antioxidant properties of morphine, Pharmacol Res. 49, 59-66 (2004).

[44] Ramalingam R., Sushruthi S., Bindu M.B., and Ravinder N.A., Antioxidant, free radical scavenging and in vitro cytotoxic studies of ethanolic extract of Leucas indica var lavandulifolia and Leucas indica var nagalapuramlana, Asian Pac J Trop Biomed. 2, 1637-1642 (2012).

[45] Manmohan et al., 2011 Manmohan S., Arindam P. and Hemendra P.S., Nitric oxide scavenging activity of synthesized methyl semicarbazone derivatives, Der Pharm Chem. 3(2), 460-467 (2011).

[46] Vijayabaskar P., and Shiyamala V., Antioxidant properties of seaweed polyphenol from Turbinaria ornate (Turner), Asian Pac J Trop Biomed. 2(1), 90-98 (2012).

[47] Huang M.H., Huang S.S., Wang B.S., Wu C.H., Sheu M.J., and Hou W.C., Antioxidant and antiinflammatory properties of Cardiospermum halicacabum and its reference compound ex vivo and in vivo, J Ethnopharmacol. 133, 743-750 (2011).

[48] Srikanth G., Manohar B.S., Kavitha C.H.N., Bhanoji Rao M.E., Vijaykumar N., and Pradeep C.H., Studies on in-vitro antioxidant activities of Carica papaya aqueous leaf extract. RJPBCS. 1(2), 59 (2010).

[49] Raja, C., Biplab, D., Nayakanti, D., and Saikat, S. Antiinflammatory, antinociceptive and antioxidant activities of Phyllanthus acidus L. extracts, Asian Pac J Trop Biomed. 2, 953961(2012). 